\title{
Climate change and state evolution
}

\author{
Giacomo Benati $^{\mathrm{a}}\left(\mathbb{0}\right.$ and Carmine Guerriero ${ }^{\mathrm{b}, 1}$ (1) \\ Edited by Margaret Levi, Stanford University, Stanford, CA, and approved February 9, 2021 (received for review November 4, 2020)
}

Despite the vast evidence on the short-run effects of adverse climate shocks on the economy, our understanding of their long-run impact on institutions is limited. To tackle such a key issue, a vast body of research has focused on ancient societies because of the limited complexity of their economies and their unparalleled experience with environmental and institutional change. Notably, the "collapse archaeology" literature has reported countless correlations consistent with the mantra that severe droughts are bound to trigger institutional crises. This conclusion, however, has been recently challenged by a stream of papers that, building on more detailed data on Bronze Age Mesopotamia and a more credible theory-based empirical strategy, have yielded the following two results. First, severe droughts pushed the elites to grant strong political and property rights to the nonelites to convince them that a sufficient part of the returns on joint investments would be shared via public good provision and, thus, to cooperate and accumulate a culture of cooperation. Second, a more favorable climate allowed the elites to elicit cooperation under less inclusive political regimes as well as a weaker culture of cooperation and, possibly, incomplete property rights. These patterns emphasize the importance of considering the asymmetric effect of droughts and, more generally, combining natural and social sciences for the evaluation of climate-related policies.

climate change | inclusive political institutions | property rights | culture of cooperation | state evolution

Despite the rapidly amassing evidence on the shortrun effect of adverse climate shocks on the economy (1), our understanding of their long-run impact on institutional evolution is limited (2).

Tackling this issue is key for the evaluation of climate-related policies, especially those directed to developing countries, and has drawn the attention of a vast body of research to ancient societies, which are the most suited laboratories for evaluating the total impact of climate change. These civilizations, indeed, are characterized by economies sufficiently simple to credibly relate variation in geographic characteristics to institutional evolution as well as an unparalleled experience with environmental and institutional change (3-6). Environmental crises, indeed, have threatened human societies since the last Ice Age, when global climate change forced humans to become increasingly reliant on the domestication of their landscapes (7), first, and to devise stable forms of state institutions easing the organization of economic cooperation, later (8). Despite the obvious importance of a deep understanding of these discontinuities, however, the majority of the archaeological literature has restricted itself to amass anecdotal accounts (9-11), first, and empirical evidence (12-15), later, on disastrous episodes in which adverse climate shocks were accompanied by social unrest and institutional decline.* Assuming that these correlations imply causal relationships, this "collapse archaeology" literature has concluded that severe droughts- "cold and dry spans" (19)—are bound to trigger epochal institutional crises and induce state dissolution $(20,21)$.

In reaction to such oversimplified, if not deterministic, analysis (22), a parallel and growing strand of literature has reported counter narratives stressing the

\footnotetext{
${ }^{a}$ Faculty of Economics and Social Sciences, Eberhard Karls Universität Tübingen, 72074 Tübingen, Germany; and bepartment of Economics, University of Bologna, 40126 Bologna, Italy

Author contributions: G.B. and C.G. designed research, performed research, analyzed data, and wrote the paper.

The authors declare no competing interest.

This article is a PNAS Direct Submission.

Published under the PNAS license.

${ }^{1}$ To whom correspondence may be addressed. Email: c.guerriero@unibo.it.

This article contains supporting information online at https://www.pnas.org/lookup/suppl/doi:10.1073/pnas.2020893118/-/DCSupplemental. Published March 31, 2021.

*An exception is constituted by some of the earliest studies that, building on differential topology theories, have emphasized the role of social complexity in driving societal collapse $(16,17)$. Combining this intuition with historical anecdotal evidence, Tainter $(9)$ concludes that states dissolve when their investment in social complexity and/or their exploitation of scarce resources reach a point of diminishing marginal returns. This tailpiece is, however, false in general since, as documented by Benati et al. (18), both instances can favor state formation if the elite's time inconsistency issues are relevant and the preferences for public goods are heterogeneous.
} 
resilience of human societies and the relevance of the strategic determinants of institutional evolution (23-25). While doing so, these contributions have emphasized two crucial drawbacks of the collapse archaeology literature. First, errors in the measurement of institutional and climate variables are greatly worsened by the usage of coarse-grained archaeological chronologies and by the reliance on the few available local proxy climate data as measures of regional-wide shocks (26). Second, the unfamiliarity of archaeological research with causal inference has greatly limited the credibility of its conclusions because of the endogeneity issues generated by both relevant unobservable factors and the even more subtle possibility of misspecifications of the empirical models embraced to study the relationships between climate change and institutional evolution (2, 27-30).

\section{A Time Inconsistency Theory of State Formation and Evolution}

To tackle these daunting issues, recent interdisciplinary research has introduced two key innovations over the extant literature. First, it has relied on more detailed simulated regional data on paleoclimatic conditions (31) as well as recent absolute chronologies more accurately linking archaeological data to institutional transitions, both available for Bronze Age Mesopotamia (32, 33). Second, it has embraced a more credible structural empirical strategy based on a long game-theoretical tradition on state evolution (34-37). The key tenet of this literature is that adverse production conditions push groups empowered by old technologies-elite-to establish the state by bestowing strong political and property rights on formerly powerless individuals-nonelite-endowed with complementary skills $(18,38)$. Formally $(18)$, assume that the elite-she-and the nonelite-he-try to cooperate in either farming or long-distance trade. The elite has both control and transfer rights to the input-i.e., either the arable land or the trading networks, whereas the nonelite can use the input to produce an output through an expensive investment and provided that the imperfectly observable environmental conditions are "favorable," e.g., the land is suitable for cultivation and the temperature is sufficiently high or the trading risks are sufficiently limited. ${ }^{\dagger}$ The elite keeps the untaxed output and to incentivize the nonelite's investment cannot commit to direct transfers but can lean on two other instruments. First, she can enact an inclusive political process, which allows the nonelite to select both the tax rate and his preferred public good. Second, she can punish the nonelite for suspected shirking by weakening his use rights to the input, e.g., shortening his land tenure $(39,40)$. This "stick" zeroes the nonelite's future payoffs from public good consumption and is expensive for the elite as well, e.g., she needs to substitute an evicted tenant.

When the expected investment return is limited-but not too tiny to avoid any cooperation (see the $R<R$ area in Fig. 1) - the nonelite cooperates only when his property rights are fully protected and he has been granted the more inclusive political process and, thus, the power to fully tax the output and produce his preferred public good (see the $R \leq R<\tilde{R}$ blue area in Fig. 1). ${ }^{\ddagger}$

\footnotetext{
${ }^{\dagger}$ The valuable output can also be interpreted as a technological innovation. ${ }^{\ddagger}$ Building on 30 preindustrial societies, Blanton and Fargher $(41,42)$ conclude, similar to Benati et al. (18), that the elites incentivize through public good provision those nonelites endowed with more relevant resources and, in turn, a strong bargaining power (43). However, different from Benati et al. (18) and Boranbay and Guerriero $(44)$, Blanton and Fargher $(41,42)$ do not clarify that the nonelite's bargaining power is mainly determined by the mix of the elite's time inconsistency issues and the heterogeneity in the preferences for the public goods and that culture is an enforcement tool for the elite and a commitment device for the nonelite.
}

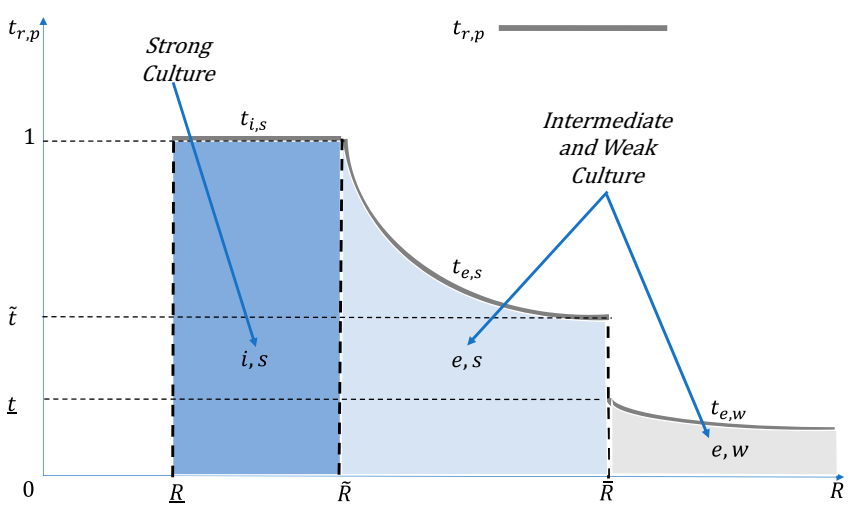

Fig. 1. Political and property rights, fiscal capacity, culture, and expected farming return. Note: $R$ indicates the expected investment return, whereas $t_{r, p}$ labels the tax rate. The pedix $r, p$ keeps track of the political regime $r$, where $i$ and e label, respectively, the more and less inclusive political institutions, as well as the property rights protection $p$, where $s$ and $w$ stand for strong and weak, respectively.

These reforms are favored by the nonelite's accumulation of a culture of cooperation, i.e., the internalized return from cooperating in any economic activity $(38,44,45)$. Intuitively, a larger implicit reward from cooperation credibly signals the nonelite's commitment to invest even in activities inducing a small payoff and, thus, a little value from public good provision. When, instead, the expected investment return is intermediate, the elite does not need to give up her preferred public good and accept full taxation to entice the nonelite, who, in turn, does not need to accumulate a large culture of cooperation to credibly signal participation (38, 44). Then, the elite does not enact the more inclusive political institution and the tax rate falls with the investment return (see the

$\tilde{R} \leq R<\bar{R}$ light blue area in Fig. 1). However, the protection of the nonelite's property must be complete to assure his participation in investment. When, finally, the investment return is sufficiently large, the elite can also restrict the nonelite's property rights (see the $R \geq \bar{R}$ gray area in Fig. 1). Punishment, however, is optimal only when production is sufficiently transparent to unmask a shirking nonelite.

The unique combination of a large elite's capacity to elicit the nonelite's cooperation through public good provision and a forceful nonelite's culture of cooperation induced by the introduction of strong political and property rights clarifies why we see in this institutional discontinuity the key feature of state formation (46). This approach differentiates us from both the anthropological and archaeological traditions, which, instead, identify state formation with the transition from collective unstructured communities to socially stratified and bureaucratically governed societies $(47,48) .^{\S}$

\section{Evidence on State Formation and Evolution in Bronze Age Mesopotamia}

The model predictions are consistent with five facts about the evolution of the earliest recorded forms of state institutions in Bronze Age Mesopotamia (8), which we summarize in the following

\footnotetext{
§Should the elite be able to enact a third political regime allowing a bureaucracy to guide fiscal policies with the goal of maximizing a weighted average of the two groups' preferences, this option will partially substitute the more inclusive political process, i.e., it will, intuitively, arise for $R_{B} \leq R<R$ and $R_{B} \geq R$. This scenario justifies the rise of tax farming under the harsh but not extreme climate of the Old Babylonian period (49).
} 
and detail in SI Appendix. First, the increasingly cold and dry climate of the end of the Urban Revolution period (3800-3300 BCE) enhanced consumption risk and, thus, the importance of irrigation infrastructures (50). The consequent need for labor organization promoted a shift of decision-making power from the former landholding groups to the temples (51). Exploiting this new role, the religious leaders obtained, over the Late Uruk period (3300-3100 $\mathrm{BCE})$, the command over public good provision (52). Furthermore, they proposed a culture of cooperation in exchange for the support in the provision of consumption risk-sharing activities, i.e., storing agricultural output, supplying grain in times of famine, accommodating loans to those in need, regulating interest rates, and organizing craft activities and short-distance exchanges (53). Second, the droughts of the onset of the Early Dynastic period (3100-2550 $\mathrm{BCE})$ decreased the agricultural yields forcing the temples to share their power with emerging palatial elites (54), who succeeded in involving a larger share of the population in farming by exchanging tenure-for-service agreements for the participation in public building projects and conscripted armies (55). Conscripted personnel gained political power and enjoyed several forms of redistribution and consumption risk-sharing, i.e., victuals, garments, access to irrigation and draft animal power in times of peace and spoils after military victories (56). Thus, the organization of a conscripted army became the nonelites' preferred public good (56). Third, the more favorable climate of the pre-Sargonic period (2550-2350 BCE) curbed the elites' need to entice the nonelites, easing the rise of royal ranks as supreme executive bodies $(57,58)$. Fourth, the harsher climate conditions of both the Akkadian and Old Babylonian periods (2350-1750 BCE) (59), and the resulting emergence of far-flung exchanges as an alternative to farming, prompted the religious and palatial elites of the polities foreseeing the largest returns on long-distance trade to share their policy-making power with the merchant guilds and produce trade-related public goods (60). Finally, over the entire Bronze Age, adverse climate shocks were never so fierce to impede any cooperation (61), and, together with the diffusion of difficult-to-observe cultivations, such as olive trees and grapevine $(18,62)$, induced reforms toward a stronger protection of the farmers' rights to land (63).

Benati et al. (18) confirm the links between these facts and the theoretical implications discussed in the previous section through data on 44 major Mesopotamian polities observed each halfcentury between 3050 and 1750 BCE. Since these societies were mainly involved in farming and evolved around one major city, whose settled center was within a $30-\mathrm{km}$ radius of the cultivated fields, Benati et al. (18) capture production conditions through novel data on the regional growing season temperature averaged within a $30-\mathrm{km}$ radius of the polity's historical coordinates and the preceding half-century. This variable is obtained by the TRACE climate model and represents the most suited proxy for the regional factors easing the domestication of the most diffused crops (31). Two are the key reasons. First, it is strongly correlated with the available local proxy data $(14,64,65)$. Second, expanding evidence implies that the growing season temperature is the key determinant of agricultural yields (66). Regarding public goods, Benati et al. (18) rely on the number of public and ritual buildings and an indicator for the organization of a conscripted army, both constructed by building on a plethora of historical analyses of the single periods and polity-specific secondary sources informed by royal inscriptions as well as land and/or trade contracts. Turning to the inclusiveness of political institutions, Benati et al. (18) construct a five-point score rising with the division of the decision-making power among the three institutionalized decision-makers, i.e., temple, extended royal family, and town elites. Similarly, the strength of the farmers' property rights to land is captured by a six-point index rising when the elites exploited their estates through leasing, renting, or tenure-for-service contracts, which assured a longer tenure to farmers, rather than through waged labor and/or when the peasants' entitlements were enforced de jure rather than de facto. The construction of both these institutional variables is based on polity-specific events in a 40-y window around each period.

Overall, this dataset assures large variation across time and space on the evolution of polities demarcated by well-defined, narrow, and stable boundaries and involved in economic activities sufficiently simple to credibly identify their geographic determinants. Regression analysis implies that both the inclusiveness of the political process and the strength of property rights are negatively-and in a statistically significant manner-related to the expected farming return, whereas only the former is positively and significantly linked to the provision of public goods and, more so, to that of the common interest good preferred by the nonelites, i.e., a conscripted army.

Even if consistent with the testable predictions, these results might be attenuated by measurement errors or they might be capturing unobserved heterogeneity and/or reverse causality (45). Crucially, none of these issues has a relevant impact on the conclusions of Benati et al. (18). Notably, they are robust to considering two key confounding factors. First, the sign, magnitude, and statistical significance of the estimated relationships remain stable when the estimated models also encompass polity and halfcentury fixed effects, which capture, respectively, all polityspecific and time-invariant and all polity-invariant and timespecific unobserved determinants of institutions and public good provision. Second, the estimated links are similar when Benati et al. (18) also evaluate the other key determinants of political and property rights and/or the provision of public goods, i.e., trade potential, severity of external and internal conflicts, degree of urbanization, rainfall, climate volatility, geographic and institutional circumscription, presence of merchant guilds, and the extent of political instability. Hence, one can conclude that these results are consistent with, if not proving, causality running from geography to institutions and from the latter to public good provision

\section{Conclusions: Policy and Methodological Implications}

The framework discussed in the previous two sections suggests that climate change has an asymmetric impact on institutional evolution whereby severe droughts induce reforms toward strong political and property rights as well as a large nonelite's cultural accumulation, whereas favorable climate conditions assure intergroup cooperation under less inclusive political regimes as well as a weaker culture and, possibly, incomplete private rights. Crucially, these predictions also shed light on recent evidence on the determinants of present-day institutional reforms in the least developed countries. To illustrate, data on the 32 most agricultural countries observed between 1961 and 2013 imply that rainfall has a solely contemporaneous inverted U-shaped effect on farming output but a $U$-shaped long run impact on the probability of democratization (67).

The analysis so far, together with recent evidence on the pivotal role of institutions in guiding the adaptation of less developed countries to climate change via cooperation (68-70), entails three key climate-related policy implications, especially relevant for developing jurisdictions. 
First, severe droughts have the short-run impact of depressing the economy but the long-run effect of eliciting an otherwise unattainable cooperation between elites and nonelites endowed with complementary skills. Then, in the aftermath of major adverse climate shocks, policymakers should calibrate their intervention to the degree of complementarity of the skills of differently powered groups. When this is large, cooperation must be elicited by favoring the participation of elites and nonelites in joint investments and, in turn, the endogenous rise of strong political and property rights as well as a culture of cooperation. When, instead, groupspecific skills are substitute, policymakers can either favor sectors fostering skill complementarity or, if such a strategy induces too large misallocations (40), transplant appropriate institutional arrangements (71). This glance from the far past offers an encouraging perspective through which to assess the full-scale impact of the present-day pandemic and take steps to turn a dramatic shortrun shock in a future success.

Second, provided that the production conditions generate a sufficiently large output to share, less inclusive political regimes can incentivize joint investments, especially if the nonelites have accumulated some culture (44). This second implication, together with the first one, speaks against the unfettered transplantation of strong political and property rights in all developing jurisdictions (71). Moreover, it squares with recent evidence on the fact that an inclusive political process can assure cooperative investments in the short run, but might become irrelevant, if not detrimental, when social and/or technological innovations deprive these joint endeavors of their role and if not accompanied by a strong culture of cooperation $(44,45)$. To elaborate, an inclusive political process does not help the monitoring of politicians by voters if the latter are not morally compelled to punish political malfeasance or if the former have weak civic virtues. Guerriero (45) confirms this remark by showing that there are fewer criminal prosecutions of members of the postwar Italian Parliaments in electoral districts in which a culture of cooperation is strong, but not in those endowed with more inclusive political institutions. Therefore, a key social goal should be to accumulate a strong culture by supporting both economic sectors in which the cooperation between elites and nonelites is necessary and consumption risk-sharing activities. As highlighted by Boranbay and Guerriero (44) and Guerriero (45), the success of the latter is particularly dependent on the diffusion of forceful norms of cooperation.

Finally, our analysis suggests that it is highly desirable to properly combine natural and social sciences when evaluating both the short- and long-run impacts of major climate shocks. Such an interdisciplinary approach requires detailed and historically rigorous data on regional climate change, institutions, and economic outcomes but also convincing theoretical models of the interplay among these forces rising the credibility of empirical tests $(5,72-74)$.

Data Availability. There are no data underlying this work.

\section{Acknowledgments}

We thank Margaret Levi, Laura Righi, and Federico Zaina for insightful suggestions and the University of Bologna for funds through the 2017 Alma Idea Grant.

1 W. Nordhaus, Climate change: The ultimate challenge for economics. Am. Econ. Rev. 190, 1991-2014 (2019).

2 D. Contreras, "Correlation is not enough. Building better arguments in the Archaeology of human environment interactions" in The Archaeology of HumanEnvironment Interactions Strategies for Investigating Anthropogenic Landscapes, Dynamic Environments, and Climate Change in the Human Past, D. Contreras, Ed. (Routledge, 2016), pp. 3-22.

3 J. H. Altschul et al., Opinion: To understand how migrations affect human securities, look to the past. Proc. Natl. Acad. Sci. U.S.A. 117, 20342-20345 (2020).

$4 \mathrm{~J}$. Haldon et al., History meets palaeoscience: Consilience and collaboration in studying past societal responses to environmental change. Proc. Natl. Acad. Sci. U.S.A. 115, 3210-3218 (2018).

5 R. C. Jackson, A. J. Dugmore, F. Riede, Rediscovering lessons of adaptation from the past. Glob. Environ. Change 52, 58-65 (2018).

6 B. J. P. Van Bavel et al., Disasters and History. The Vulnerability and Resilience of Past Societies (Cambridge University Press, 2020).

$7 \mathrm{~N}$. Roberts et al., Human responses and non-responses to climatic variations during the last glacial-interglacial transition in the eastern mediterranean. Quat. Sci. Rev. 184, 47-67 (2018).

8 M. Liverani, The Ancient Near East: History, Society, Economy (Routledge, 2014).

9 J. A. Tainter, The Collapse of Complex Societies (Cambridge University Press, 1988).

10 J. Diamond, Collapse: How Societies Choose to Fail or Succeed (Viking Press, New York, 2005).

11 G. D. Middleton, Understanding Collapse: Ancient History and Modern Myths (Cambridge University Press, 2017).

12 Q. Pei, D. D. Zhang, H. F. Lee, G. Li, Climate change and macro-economic cycles in pre-industrial Europe. PLoS One 9, e88155 (2014).

13 H. N. Dalfes, G. Kukla, H. Weiss, Eds., Third Millennium BC Climate Change and Old World Collapse (Springer, 1997).

14 A. Sinha et al., Role of climate in the rise and fall of the Neo-Assyrian Empire. Sci. Adv. 5, eaax6656 (2019).

15 J. G. Manning et al., Volcanic suppression of Nile summer flooding triggers revolt and constrains interstate conflict in ancient Egypt. Nat. Commun. 8, 900 (2017).

16 C. Renfrew, Trajectory discontinuity and morphogenesis: The implications of catastrophe theory for archaeology. Am. Antiq. 43, 203-222 (1978).

17 C. Renfrew, "Systems collapse as social transformation. Catastrophe and anastrophe in early state societies" in Transformations: Mathematical Approaches to Culture Change, C. Renfrew, K. L. Cooke, Eds. (Academic, New York, 1979), pp. 481-506.

18 G. Benati, C. Guerriero, F. Zaina, The origins of political institutions and property rights: Time inconsistency vs. opacity. SSRN [Preprint] (2019). https://doi.org/10. 2139/ssrn.3395353 (Accessed 18 March 2021).

19 H. Weiss, Ed., Megadrought and Collapse. From Early Agriculture to Angkor (Oxford University Press, 2017).

20 R. B. Gill et al., Drought and the Maya collapse. Anc. Mesoam. 18, 283-302 (2007).

21 G. Woolf, "Archaeological narratives of the collapse of complex societies" in Decline and Decline-Narratives in the Greek and Roman World, Proceedings of a Conference held in Oxford in March 2017, T. Minamikawa, Ed. (Kyoto University, 2017), pp. 113-122.

22 V. P. J. Arponen et al., Environmental determinism and archaeology. Understanding and evaluating determinism in research design. Archaeol. Dialogues 26, 1-9 (2019).

23 P. Halstead, J. O'Shea, Eds., Bad Year Economics: Cultural Responses to Risk and Uncertainty (Cambridge University Press, 1989).

24 N. Yoffee, G. L. Cowgill, Eds., The Collapse of Ancient States and Civilizations (University of Arizona Press, Tucson, AZ, 1988).

25 P. A. McAnany, N. Yoffee, Eds., Questioning Collapse: Human Resilience, Ecological Vulnerability, and the Aftermath of Empire (Cambridge University Press, 2009).

26 K. W. Butzer, G. H. Endfield, Critical perspectives on historical collapse. Proc. Natl. Acad. Sci. U.S.A. 109, 3628-3631 (2012).

27 D. D. Zhang et al., The causality analysis of climate change and large-scale human crisis. Proc. Natl. Acad. Sci. U.S.A. 108, 17296-17301 (2011).

28 D. S. Davis, Studying human responses to environmental change: Trends and trajectories of archaeological research. Environ. Archaeol. 25, 367-380 (2020).

29 J. A. d'Alpoim Guedes, S. A. Crabtree, R. K. Bocinsky, T. A. Kohler, Twenty-first century approaches to ancient problems: Climate and society. Proc. Natl. Acad. Sci. U.S.A. 113, 14483-14491 (2016). 
30 K. W. Butzer, Collapse, environment, and society. Proc. Natl. Acad. Sci. U.S.A. 109, 3632-3639 (2012).

$31 \mathrm{~F}$. He, "Simulating transient climate evolution of the last deglatiation with CCSM3," PhD dissertation, University of Wisconsin-Madison (2011).

32 W. Sallaberger, I. Schrakamp, Eds., ARCANE III. History \& Philology (Brepols, Turnhout, Belgium, 2015).

33 S. W. Manning et al., Integrated tree-ring-radiocarbon high-resolution timeframe to resolve earlier second millennium BCE mesopotamian chronology. PLoS One 11, e0157144 (2016).

34 D. C. North, B. R. Weingast, Constitutions and commitment: The evolution of institutions governing public choice in seventeenth-century England. J. Econ. Hist. 49, 803-832 (1989).

35 Y. Barzel, E. Kiser, The origins of democracy in England. Ration. Soc. 3, 396-422 (1991).

36 R. K. Fleck, F. A. Hanssen, The origins of democracy: A model with application to ancient Greece. J. Law Econ. 49, 115-146 (2006).

37 R. B. Myerson, The autocrat's credibility problem and foundations of the constitutional state. Am. Polit. Sci. Rev. 102, 125-139 (2008).

38 G. Benati, C. Guerriero, The origins of the state: Technology, cooperation and institutions. J. Institutional Econ., 10.1017/S1744137420000569 (2020).

39 C. Guerriero, Endogenous property rights. J. Law Econ. 59, 313-358 (2016).

40 C. Guerriero, Property rights, transaction costs, and the limits of the market. SSRN [Preprint] (2017). https://doi.org/10.2139/ssrn.3058095 (Accessed 18 March 2021).

41 R. E. Blanton, L. Fargher, Collective Action in the Formation of Pre-Modern States (Springer, New York, 2008).

42 R. E. Blanton, L. Fargher, How Humans Cooperate. Confronting the Challenges of Collective Action (University of Colorado Press, Boulder, 2016).

43 M. Levi, Of Rule and Revenue (University of California Press, Los Angeles, 1988).

44 S. Boranbay, C. Guerriero, Endogenous (in)formal institutions. J. Comp. Econ. 47, 921-945 (2019).

45 C. Guerriero, Endogenous institutions and economic outcomes. Economica 87, 364-405 (2020).

46 E. Berwick, C. Fotini, State capacity redux: Integrating classical and experimental contributions to an enduring debate. Annu. Rev. Polit. Sci. 21, 71-91 (2018).

47 H. T. Wright, Early state dynamics as political experiment. J. Anthropol. Res. 62, 305-319 (2006).

48 D. S. Sandeford, Organizational complexity and demographic scale in primary states. R. Soc. Open Sci. 5, 171137 (2018).

49 M. Van de Mieroop, Production and commerce in the old Babylonian period. Riv. Stor. Econ. 31, 79-96 (2015).

50 M. Altaweel, Southern Mesopotamia: Water and the rise of urbanism. Wiley Interdiscip. Rev. Water 6, 1-6 (2019).

$51 \mathrm{~J}$. M. Renger, Institutional, communal, and individual ownership or possession of arable land in ancient Mesopotamia from the end of the fourth to the end of the first millennium B.C. Chic. Kent Law Rev. 71, 269-319 (1995).

52 R. J. Matthews, A. Richardson, Cultic resilience and inter-city engagement at the dawn of urban history: Protohistoric Mesopotamia and the "city seals," 3200-2750 BC. World Archaeol. 50, 723-747 (2018).

53 D. Charpin, La Vie Méconnue des Temples Mésopotamiens (Les Belles Lettres, Collège de France, Paris, 2017).

54 M. Staubwasser, H. Weiss, Holocene climate and cultural evolution in late prehistoric-early historic West Asia. Quat. Int. 66, 372-387 (2006).

55 P. Steinkeller, The reluctant en of inana-or the persona of Gilgameš in the perspective of Babylonian political philosophy. J. Anc. Near East. Hist. 5, 149-177 (2019).

56 S. Richardson, "Mesopotamia and the 'new' military history" in Recent Directions in the Military History of the Ancient World, L. L. Brice, J. T. Roberts, Eds. (Regina Books, Claremont, CA, 2011), pp. 11-51.

57 S. J. Garfinkle, "Ancient near Eastern city-states" in Oxford Handbook of the State in the Ancient Near East and the Mediterranean, P. F. Bang, W. Scheidel, Eds. (Oxford University Press, 2013), pp. 94-119.

58 L. Ristvet, "'Assyria' in the third millennium BCE" in A Companion to Assyria, E. Frahm, Ed. (Wiley-Blackwell, 2017$),$ pp. 36-56.

59 S. A. Carolin et al., Precise timing of abrupt increase in dust activity in the Middle East coincident with 4.2 ka social change. Proc. Natl. Acad. Sci. U.S.A. 116, 67-72 (2019).

60 G. Barjamovic, "Interlocking commercial networks and the infrastructure of trade in Western Asia during the Bronze Age" in Trade and Civilisation: Economic Networks and Cultural Ties from Prehistory to the Early Modern Era, K. Kristiansen, T. Lindkvist, J. Myrdal, Eds. (Cambridge University Press, 2018 ), pp. 113-142.

61 S. Riehl, "Climate and agricultural decision making: Environmental constraints and economic development in near Eastern sites between 5000-3500 Cal BP" in Between Sand and Sea: The Archaeology and Human Ecology of Southwestern Asia. Festschrift in Honor of Hans-Peter Uerpmann, N. J. Conard, P. Drechsler, A. Morales, Eds. (Kerns Verlag, Tübingen, Germany, 2011), pp. 147-166.

62 S. Riehl, Archaeobotanical evidence for the interrelationship of agricultural decision-making and climate change in the ancient near east. Quat. Int. 197, 93-114 (2009).

63 C. Wilcke, Early Ancient Near Eastern Law. A History of Its Beginnings: The Early Dynastic and Sargonic Periods (Eisenbrauns, Winona Lake, IN, ed. 2, 2007).

64 M. Bar-Matthews, A. Avner, A. Kaufman, Late Quaternary paleoclimate in the eastern Mediterranean region from stable isotope analysis of speleothems at Soreq Cave, Israel. Quat. Res. 47, 155-168 (1997).

65 M. Altaweel et al., New insights on the role of environmental dynamics shaping Southern Mesopotamia: From the Pre-Ubaid to the early Islamic period. Iraq 81 , 23-46 (2019).

66 C. Zhao et al., Temperature increase reduces global yields of major crops in four independent estimates. Proc. Natl. Acad. Sci. U.S.A. 114, 9326-9331 (2017).

67 A. Ciccone, A. Ismailov, Democratic tipping points. Working paper, Mannheim University (2020). https://www.antoniociccone.eu/wp-content/uploads/2020/06/ democratic-tipping-points-31052020.pdf. Accessed 18 March 2021.

68 M. Yomo et al., Climate change adaptation in semi-arid ecosystems: A case study from Ghana. Clim. Risk Manage. 27, 100206 (2020).

69 C. P. Mubaya, P. Mafongoya, The role of institutions in managing local level climate change adaptation in semi-arid Zimbabwe. Clim. Risk Manage. 16, 93-105 (2017).

70 A. Agrawal, "Local institutions and adaptation to climate change" in Social Dimensions of Climate Change. Equity and Vulnerability in a Warming World, R. Mearns, A. Norton, Eds. (The World Bank, Washington, DC, 2010), pp. 173-199.

71 C. Guerriero, Endogenous legal traditions and economic outcomes. J. Comp. Econ. 44, 416-433 (2016).

72 B. J. P. van Bavel et al., Climate and society in long-term perspective: Opportunities and pitfalls in the use of historical datasets. Wiley Interdiscip. Rev. Clim. Change 10, e611 (2019).

73 M. A. Turner, J. S. Rosenthal, J. Chen, C. Hao, Adaptation to climate change in preindustrial Iceland. Am. Econ. Rev. 102, 250-255 (2012).

74 R. Allan et al., Toward integrated historical climate research: The example of atmospheric circulation reconstructions over the earth. Wiley Interdiscip. Rev. Clim. Change 7, 164-174 (2016). 